\title{
Computer games development and appreciative learning approach in enhancing students' creative perception
}

\begin{abstract}
Creativity is an important entity in developing human capital while computer games are the current generationôs contemporary tool. This study focused on the teaching of computer games development in order to enhance the creative perception of secondary school children. The study applied randomised subjects, with control group experimental design, which involved 69 Malaysian form one students, aged 13 ï 14 year-old. Different pedagogical strategies were being investigated on the abilities to enhance studentsôcreative perception. Treatment group adopted appreciative learning approach, which was based on Appreciative Inquiry (AI) theory. Meanwhile, control group adopted self-paced learning, followed by doit-yourself session. Previous studies indicated that although appreciative learning approach is still in its infancy development, the approach is gaining its momentum in educational settings as it focuses on strengthening a personôs capacities and potential. Studentsô creative perception was assessed using Khatena-Torrance Creative Perception Inventory (KTCPI). It was found students in treatment group gained a mean score of 71.82 , which was significantly higher at .05 level of significance compared to the mean score of 50.49 exhibited by the control group. Yet, both treatment and control groups showed significant increases in pre-topost-test scores. Dimensions within KTCPI were further analysed in order to present a better picture of studentsô creative perception. As a conclusion, different pedagogical strategy generated different level of creative perception enhancement.
\end{abstract}

Keyword: Improving classroom teaching; Pedagogical issues; Secondary education; Teaching/learning strategies 